\title{
ESTUDO COMPARATIVO DAS MÉDIAS MÓVEIS, DOS INDICES BACILOSCÓPICO E MORFOLÓGICO, EM PACIENTES DE HANSENIASE VIRCHOVIANA TRATADOS PELA RIFAMPICINA E PELA DIAMINO-DIFENIL-SULFONA
}

\author{
Walter Belda : \\ Leontina C. Margarido ** \\ José Maria Marlet $* * *$ \\ Ednir A. L. W. Martinez $* * ; *$ \\ Teresa J. A. E. Kliemann **: \\ Clovis Lombardi ****:* \\ Walter Belda Jr. $* * * ; *:$
}

RSPUB $9 / 452$

BELDA, W. et al. Estudo comparativo das médias móveis, dos indices baciloscópico e morfologico, em pacientes de hanseniase virchoviana tratados pela ritampicina e pela diamino-difenil-sulfona. Rev. Saúde públ., S. Paulo, 13: $80-91,1979$.

REsUMo: São apresentados resultados clinicos e baciloscópicos obtidos, em estudo comparativo, na experimentaça terapêtutica da ação da rifampicina e diamino-difenil-sulfona na hanseniase virchoviana. Respectivamente 24 e 23 pacientes, relativamente homogeneizados, foram observados por um periodo minimo de 12 meses e máximo de 2t. É ressaltada a superioridade da ação da rifampicina, nos primeiros meses, em termos clinicos, e de reduçáo do número de bacilos viáveis. É recomendado, pelo menos como etapa inicial do tratamento, o emprego da rifampicina na terapêtitica da hanseniase virchoviana.

UNITERMos: Rifampicina. Hanseniase, quinioterapia.

\section{INTRODUÇÃO}

De muito a hanseniase vem sendo aceita, nas regióes intertropicais, cono importante problema de saúde pública. Predominante em populações de baixas cundições sócio- econômicas e de características urbanas, no Brasil, em termos de pacientes registrados, apresenta há decênios um coeficiente de prevalência constante de 1,3 o/or. Em

* Do Departamento de Epidemiologia da Faculdade de Saúde Pública da USP - Ar. Dr. Arnaldo, 715 - 01255 - São Paulo, SP - Brasil e do Instituto de Saúde - Ar. Dr. Enéas Carvalho de Aguiar, 188 - 05403 - São Paulo, SP - Brasil.

* Do Hospital Pe. Bento. Gopoura - 07000 - Guarulhos, SP - Brasil.

** Da Faculdade de Ciências Médicas da Pontifícia Unifersidade Católica de Campinas Rua Marechal Deodoro. 1099 - 19100 - Campinas - SP - Brasil.

Do Instituto de Saúcle.

**: Do Departamento de Epidemiologia da Faculdade de Saúde Pública da USP.

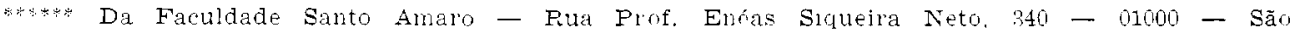
Paulo, SP - Brasil. 
BELDA, W. et al. Estudo comparativo das médias móveis, dos indices baciloscópieo e morfológico, em pacientes de hanseníase virchoviana tratados pela rifampicina e pela diaminodifenil-sulfona. Rev. Saúde públ., s. Paulo, 13:80-91, 1979.

aproximação otimista, podemos nos fjxar em 2,7 o/oo.

Embora exemplos frisantes encareçam a importância do meio na sua expansão, até o momento as medidas de controle tem se restringido ao nível secundário - diagnóstico e tratamento.

Se o diagnóstico do grupo indiferenciado implica experiência dermato-hansenológica maior, o dos tipos evoluídos é, no geral, surpreendentemente simples até para leigos.

O tratamento bem orientado impede a evolução dos casos indiferenciados para as formas contagiantes e, nestas, reduz ou inativa seu potencial de infecção.

De introdução recente na longa história da moléstia, a diamino-difenil-sulfona (DDS), apesar de não apresentar atributos de droga ideal, continua como primeira escolha, válida, nos programas sanitários. Ao seu lado, um crescente número de fármacos ativos enriquecem o arsenal terapêutico, em que pesem suas naturais limitações.

Entre estes, sobressai a Rifampicina, antibiótico semi-sintético pertencente ao grupo das rifamicinas $\mathrm{S}$ V. Sua introdução na terapêutica anti-hanseniase se deu em 1963, com os trabalhos de Opromolla ${ }^{\circ}$. Nessa ocasião, com sua percepção privilegiada, Souza Lima ${ }^{12}$ afirmava: "Este antibiótico, a persistirem os resultados até agora registrados em nossos grupos-piloto, passará a ocupar o primeiro lugar entre os medicamento empregados no tratamento da lepra".

No entanto, só a partir de 1970 a rifampicina passou a merecer atenção maior na literatura especializada. Neste ano, Baccareda Boy e Bertamino ${ }^{1}$; Leiker e Kamp ${ }^{4}$; Meneguine e col.5; Pisacane e col.7; Rees e col. ${ }^{\S}$; Trimigliozzi e col. ${ }^{13}$ já encareciam seu rápido efeito bactericida e a precocidade das melhoras clínicas.

Os estudos clínicos de Shepard e col.10,11, em 1972, e Rees ${ }^{9}$ (1975) mostraram que a rifampicina determinava queda rápida nos indices morfológicos, e bacilos não viáveis foram obtidos após 3 a 4 dias de trata- mento, tornando assim os pacientes rapidamente em não-infectantes.

Em ensaio preliminar para esta comunicação (Belda e col.2, 1974) empregamo-la em pacientes clinicamente sulfono-resistentes, com resultados animadores e, sem detecção de alterações hematológicas, hepáticas ou renais no período observado.

Horgenzeil e Rees ${ }^{3}$ (1975) afirmam que os pacientes podem se tornar negativos com uma simples dose de $1.500 \mathrm{mg}$ de rifampicina.

Assim embasados, iniciamos este experimento, procurando verificar, principalmente sob o aspecto do comportamento bacilar, as ações do fármaco em relação à DDS.

\section{METODOLOGIA E CASUfSTICA}

De início se fez necessário contornar dois obstáculos: a homogeneização da amostra e a observação em regime hospitalar.

E hoje difícil manter-se pacientes por tempo prolongado em hospitais ainda fortemente impregnados do passado político de internação compulsória. De 1974 a 1976 foi possível hospitalizar, no Hospital Santo Angelo da Divisão de Hospitais de Dermatologia Sanitária da Secretaria da Saúde do Estado de São Paulo, 72 pacientes virgens de tratamento para, aleatoriamente, serem submetidos aos esquemas terapêticos previstos. No transcurso do experimento houve necessidade de seleções que, de certa forma, comprometeram a causalização preliminar.

Assim, no intuito de homogeneização, incluimos somente aqueles que tinham no máximo 10 anos de tempo presumivel de doença, ficando a moda em 6 anos. Excluimos para esta avaliação os que apresentaram indices morfológicos iniciais muito distantes dos encontrados rotineiramente.

Em nossa experiência, os casos de percentuais altos de bacilos integros não constituem a regra. 
BELDA, W, et al. Estudo comparativo das médias móveis, dos índices baciloscópico e morfológico, em pacientes de hanseníase virchoviana tratados pela rifampicina e pela diaminodifenil-sulfona. Rev. Saúde públ., S. Paulo, 13:80-91, 1979.

Para o estudo baciloscópico fixamos oito colheitas, em quatro locais aproximadamente simétricos: narinas, cotovelos, nádegas e joelhos. Foram escolhidas áreas de infiltração ou de pequenas lesões sólidas, evitando-se hansenomas mais evidentes.

Estas limitações reduziram o grupo a 23 pacientes para DDS e 24 para rifampicilina. Por sorteio, incluímos como extras pacientes de hanseniase tuberculóide reacional e hanseniase dimorfa, respectivamente 3 e 1 para o grupo de DDS e 2 e 3 para o grupo da rifampicina.

Dos 47 pacientes, apenas 5 permaneceram hospitalizados nos dois anos programados; todos completaram 12 meses de ubservação.

O diagnóstico inicial foi confirmado por duas biópsias de cada caso. Embora revistos mensalmente, para o presente relato anotamos os dados bimensais.

O grupo sob tratamento con DDS recebeu $100 \mathrm{mg}$ diárias, e o da rifampicina 600 $\mathrm{mg}$, independentemente do sexo, idade, peso e duração da moléstia.

Os resultados referentes à evolução dos indices morfológicos foram submetidos ao teste de Kolmogorow-Smirnov e para os indices baciloscópicos usamos o teste de Wald-Worforwitz.

\section{RESULTADOS}

Os resultados obtidos encontram-se nas Tabelas 1 a 5 e nas Figuras 1 a 6.

\section{COMENTARIOS}

O extremo polimorfismo das manifestaçōes clínico-dermatológicas associado às variações individuais e à evolução crônica, com episódios nem sempre esperados, tornam difícil o estabelecimento de padrōes necessários às comparações. A seleção de grupos homogêneos, em número significativo, em termos de quadros clínicos, sexo, cor, idade, tempo de doença, entre outros enfrenta óbices desconcertantes. Desse modo, a avaliação clinica tem muito de subjetiva.

Com tais ressalvas, procuramos sintetizar nossos achados em torno de aspectos mais gerais, já que a análise de cada caso não só estenderia demasiadamente este relato, como se perderia em minúcias.

\section{$D D S$}

A larga experimentação que se tem do emprego da sulfona (DDS) na hanseníase virchoviana, já permitiu estabelecer, de modo geral, uma seqüência de modificações que se processam lenta e progressivamente. Em cerca de $30 \%$ dos casos, esse evoluir esperado é acompanhado, de reações tipo eritema nodoso.

Nos primeiros meses, são mais evidentes as melhoras das lesões do palato e mucosas nasais, assim como das ulcerações específicas. Pouco mais tardiamente, as infiltrações esmaecem e as lesões menores ou mais recentes desaparecem. É a partir do quarto mês que os sinais de regressão das lesões maiores ou mais antigas são mais evidentes. De modo geral, quando tudo caminha normalmente, a cura clínica processa-se entre 3 e 5 anos.

Nus casos do presente relato, em regra, foi 0 que observamos até 2 anos, nos pacientes que receberam DDS. Tivemos duas exceções sensíveis. $O$ caso no 13 de rifampicina iniciara o tratamento com DDS. Desde o primeiro mês, as lesões se acentharam, com piora progressiva e sinais de intulerância. No terceiro mês suspendemos a medicação e, após 20 dias, iniciamos a rifampicina com ótima tolerância e evolução muito boa. O caso $n^{\circ} 23$ apresentou melhoras até o quarto mês, a partir de então surgiram lesões novas, aumento dos indices baciloscópico e morfológico, com surtos irtensos de eritema nodoso. Após o décimo mês, mudamos o esquema terapêutico. 
BELDA, W. et al. Estudo comparativo das médias móveis, dos índices baciloscópico e morfológico, em pacientes de hanseniase virchoviana tratados pela rifampicina e pela diaminodifenil-sulfona, Rev. Saúde públ., S. Paulo, 13:80-91, 1979.

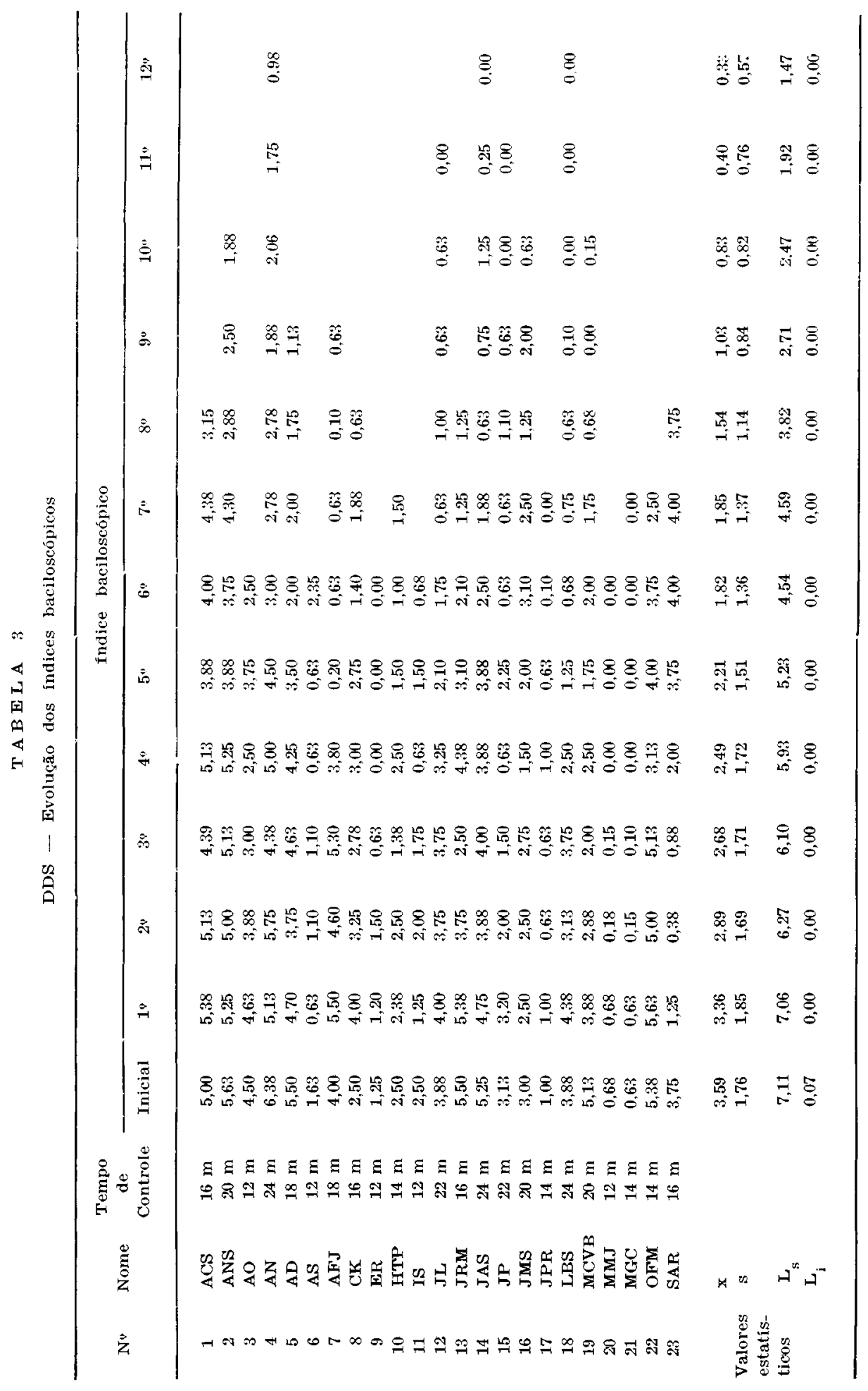


BELDA, W. et al. Estudo comparativo das médias móveis, dos indices baciloscópico e morfológico, em pacientes de hanseníase virchoviana tratados pela rifampicina e pela diaminodifenil-sulfona. Rev. Saúde públ., S. Paulo, 13:80-91, 1979.

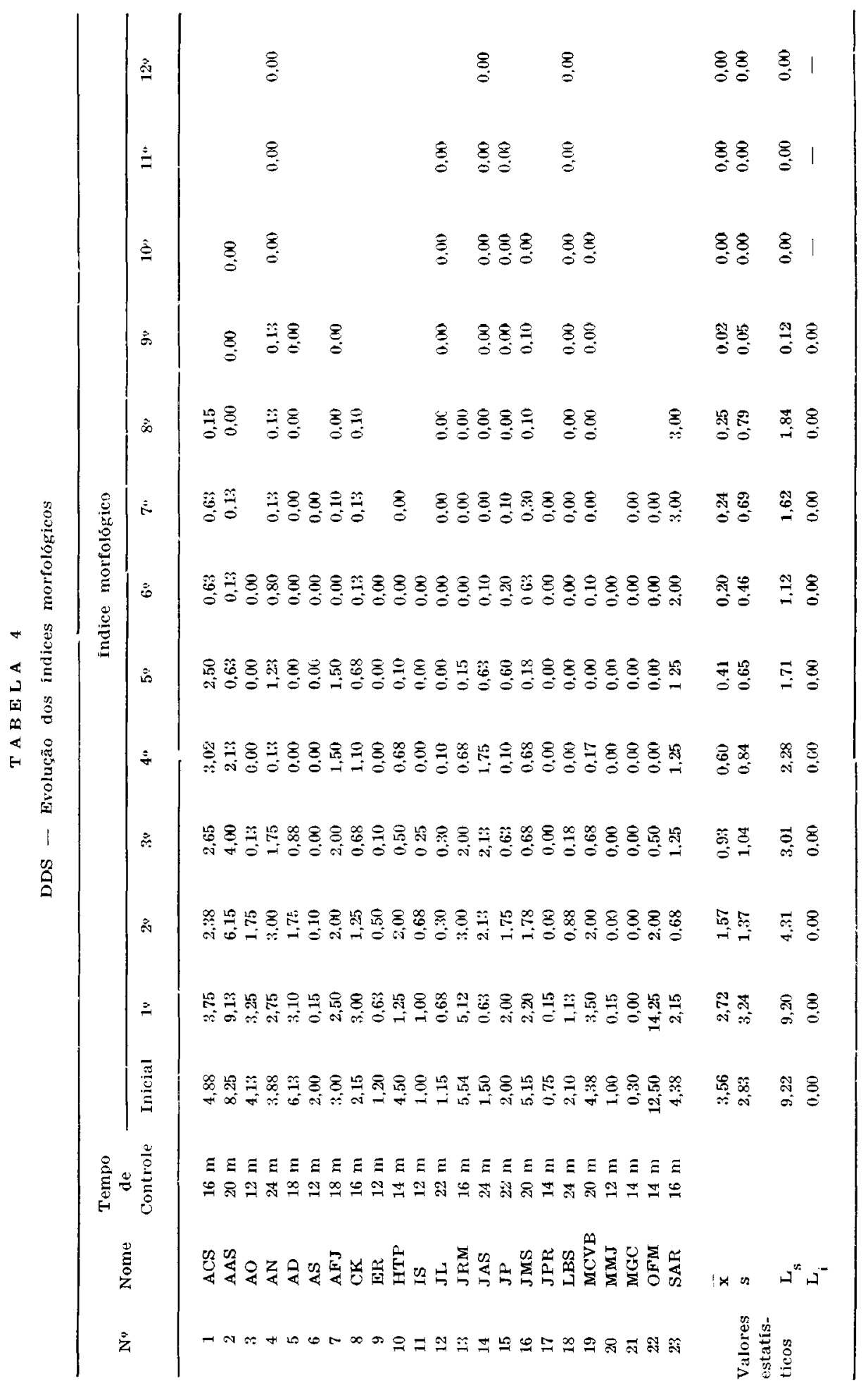


BELDA. W. et al. Estudo comparativo das médias móveis. dos indices baciloscópico e mortológico, em pacientes de hanseniase rirchoviana tratados pelá rifampicina e pela diaminodifenil-sulfona. Rer. Saúde pribl., S. Paulo, 13:80-91, 1979.

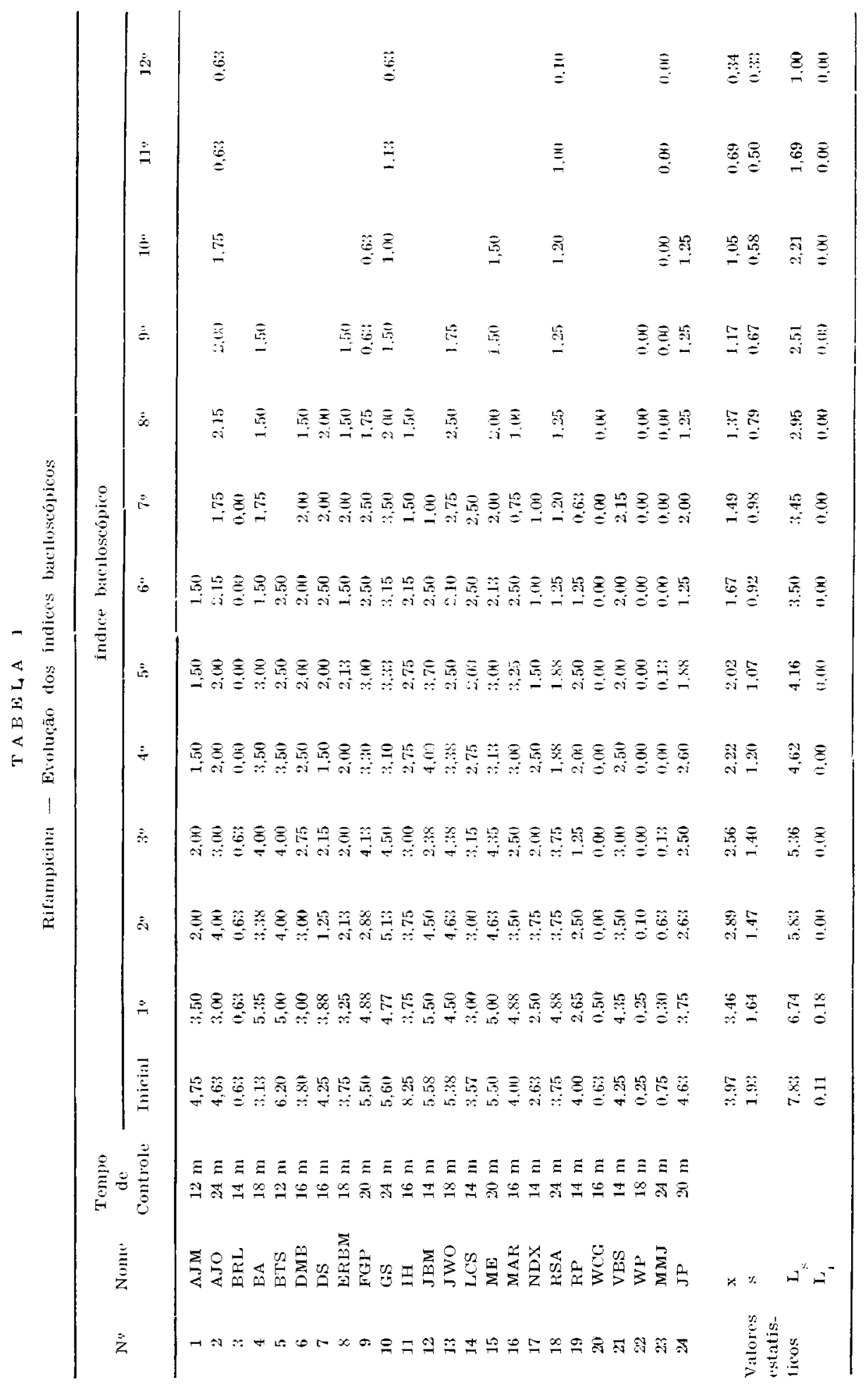


BELDA. W. et al. Estudo comparatiro das médias móreis, dos índices baciloscópico e morfológico, em pacientes de hanseníase virchoriana tratados pela rifampicina e pela diaminodifenil-sulfona. Rer. Saúde públ., S. Paulo. 13:80-91. 1979.

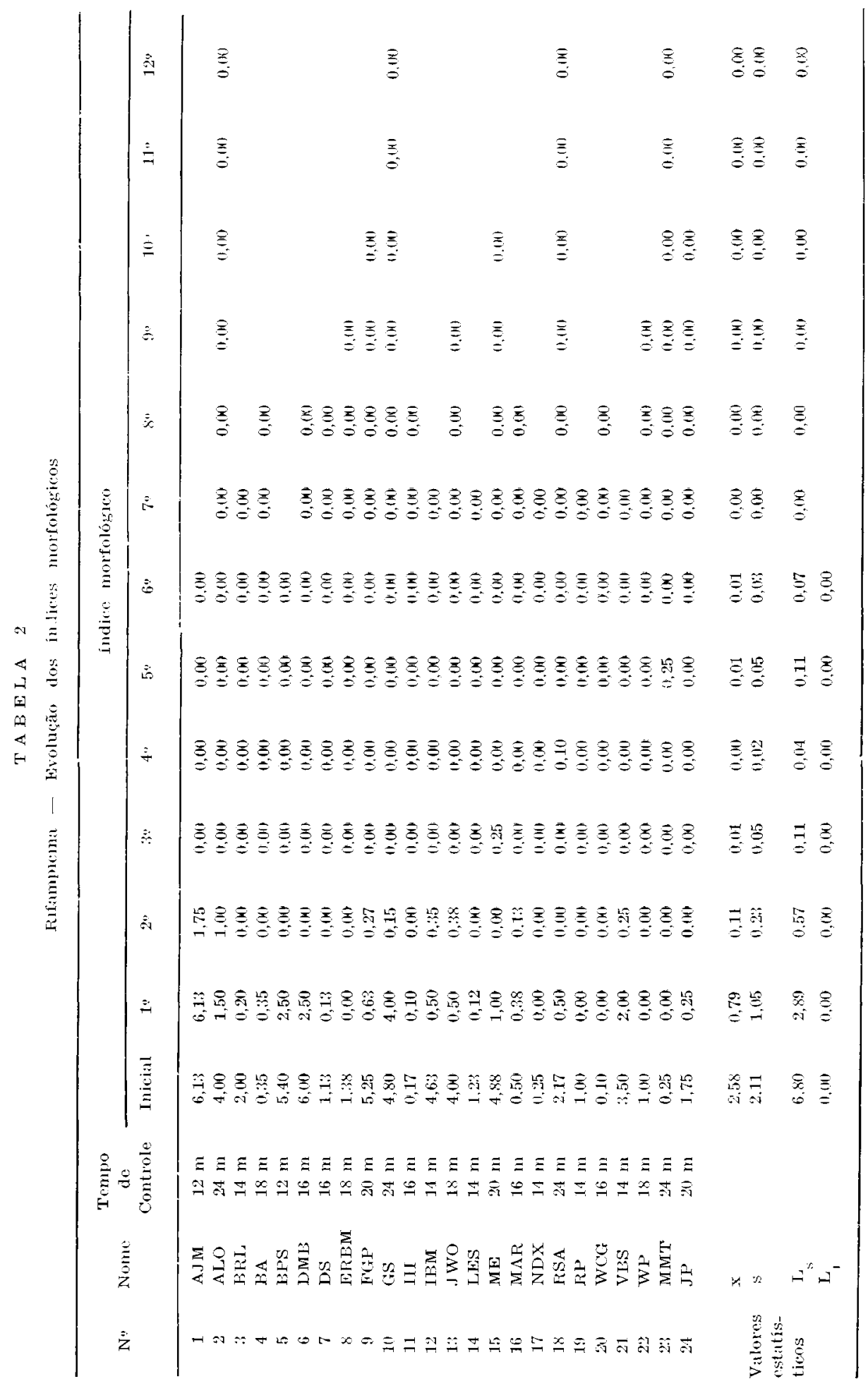


BELDA, W, et al. Estudo comparativo das médias móveis, dos indices baciloscópico e morfológico, em pacientes de hanseníase virchoviana tratados pela rifampicina e pela diaminodifenil-sulfona. Rev. Saúde públ., S. Paulo, 13:80-91, 1979.

TA B E L A 5

Estudo comparativo da ação da rifampicina e do DDS no tratamento da hanseníase virchoviana (fndices Médios)

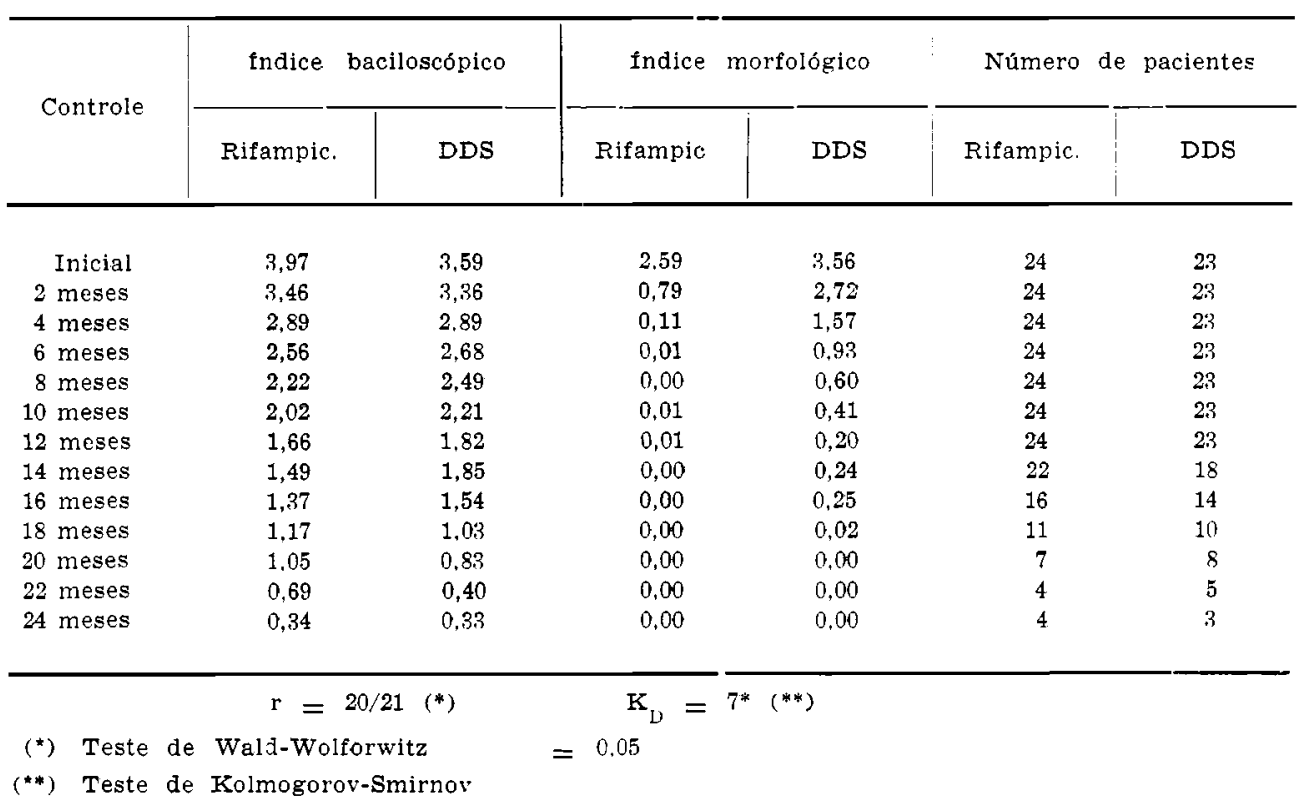

TABELA 6

Médias móveis

\begin{tabular}{lcccc}
\hline Tempo & \multicolumn{2}{c}{ Indice baciloscópico } & \multicolumn{2}{c}{ fndice morfológico } \\
& Rifampicina & DDS & Rifampicina & DDS \\
\hline 2 meses & 3,37 & 3,28 & 1,16 & 2,56 \\
4 meses & 2,96 & 2,98 & 0,30 & 1,68 \\
6 meses & 2,56 & 2,69 & 0,07 & 1,03 \\
8 meses & 2,27 & 2,46 & 0,01 & 0,65 \\
10 meses & 1,97 & 2,17 & 0,01 & 0,40 \\
12 meses & 1,69 & 1,96 & 0,01 & 0,30 \\
14 meses & 1,48 & 1,74 & 0,00 & 0,24 \\
16 meses & 1,31 & 1,47 & 0,00 & 0,18 \\
18 meses & 1,20 & 1,13 & 0,00 & 0,09 \\
20 meses & 0,97 & 0,79 & 0,00 & 0,00 \\
22 meses & 0,69 & 0,55 & 0,00 & 0,00 \\
\hline
\end{tabular}


BELDA. W, et al. Estudo comparativo das médias móreis, dos indices baciloscópico e morfológico. em pacientes de hanseniase rrchoviana tratados pela rifampicina e pela diaminodifenil-sulfona. Rer. Saude puibl., S. Paulo. 13:80-91, 1979.

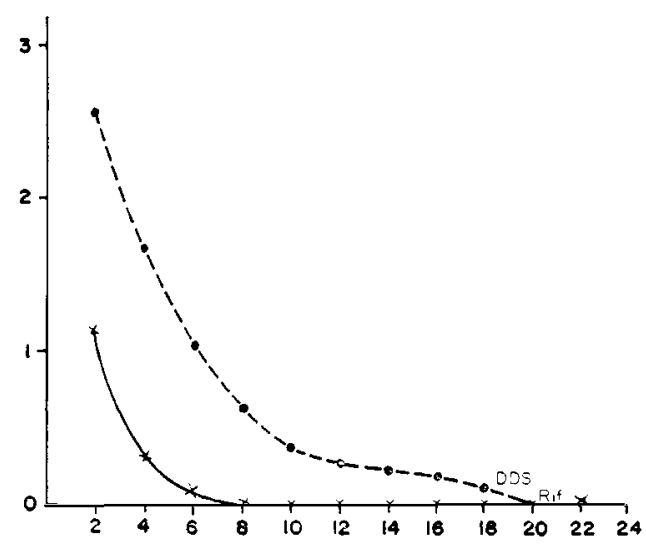

Fig, 1 - Médias móveis dos indices morfológicos de bacilos de hansenunos tratados con Rifampicina ou DDS.

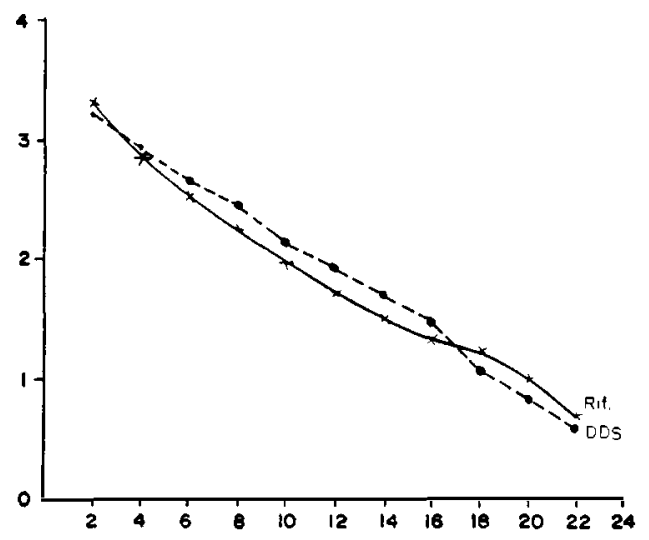

Fig, 2 - Médias móveis dos índices baculoscópicos hansenianos tratados com Rifampicina ou DDS.

Por outro lado, 7 casos $(30,4 \%)$ evidenciaram melhoras clínicas nitidas. No periodo de 12 meses, 7 casos $(30,4 \%)$ fizeram reaçōes de eritema nodoso, das quais 5 após o quarto mês.

Os casos B e TR nāo incluidos nas Tabe. las evoluiram satisfatoriamente desde 0 segundo mês.

\section{Rifampicina}

Com relação à rifampicina, a experiência que se vem acumulando mostra que, de modo geral, a sequiência é a mesma. A diferença fundamental é o tempo.

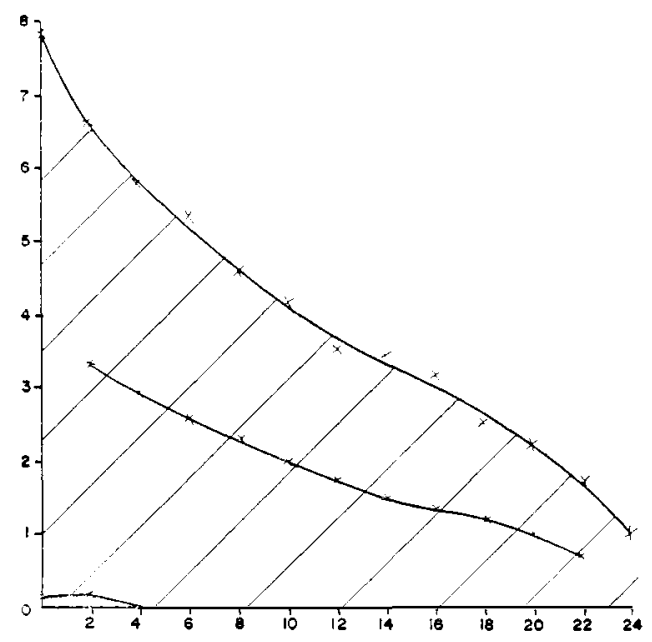

Fig. 3 - Mfrdias e limites de confiança $95 \%$ los indices bacloscóproos de hansenianos tratados com Rifampicina.

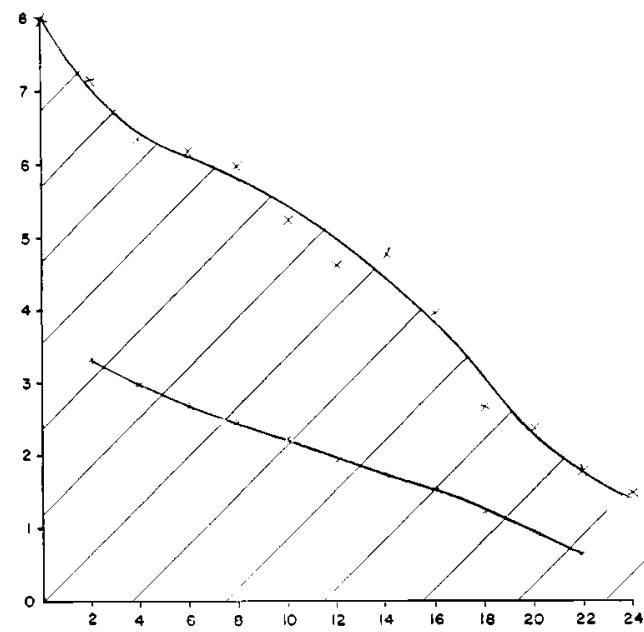

Flg. 4 - Médlas e limites de confiança $95 \%$ para o indice bacloscópico de hansenianos tratados com DDS. 
BELDA, W. et aI, Estudo comparativo das médias móveis, dos indices baciloscópico e morfológico, em pacientes de hanseniase virchoriana tratados pela rifampicina e pela diaminodifenil-sulfona. Rev. Saude puibl., S. Paulo, 13:80-91, 1979.

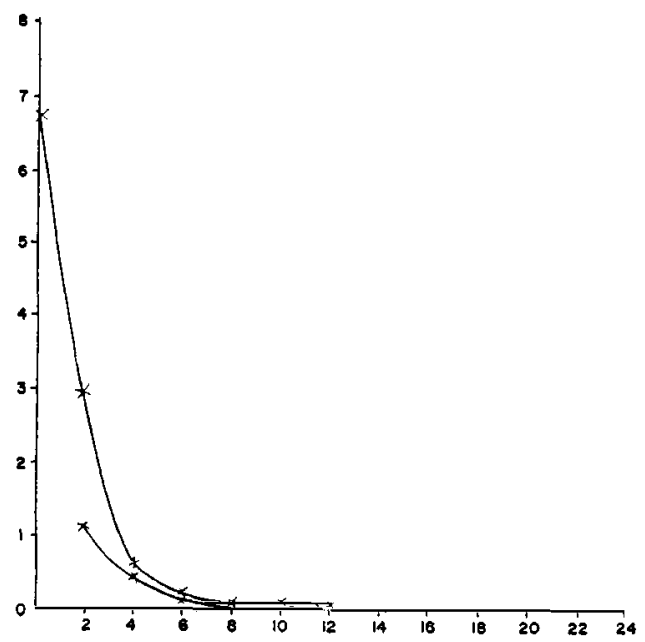

Fig. 5 - Médias e limites de confiança $95 \%$ para o indice morfológico de bacilos de hansenianos tratados com Rifampicina,

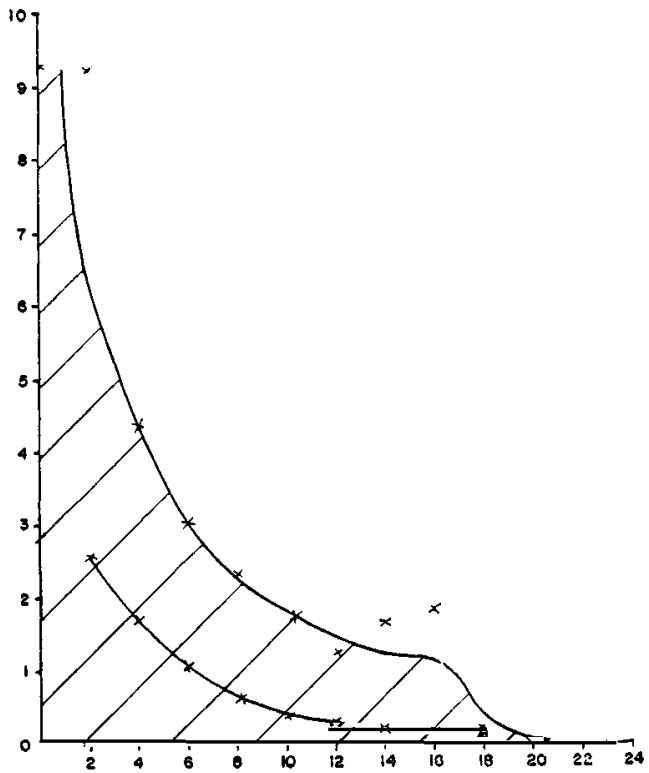

Fig. 6 - Médias e limites de confiança $95 \%$ para o indice morfológico de bacilos de hansenianos tratados com DDS.
A desobstrução nasal foi relatada já na primeira semana de tratamento, acompanhada de sensação de bem-estar e referências cle aumento de apetite.

Dos 24 casos assim tratadus, exceção feita aos pacientes de nos 7,14 e 25 , todos apresentaram desaparecimento de pecuenas lesões sólidas, amolecimento de hansenomas e esmaecimento nitido da infiltração entre o) primeiro e segundo mês.

No entanto, o eritema nodoso foi mais irequiente e mais precoce. En 10 casos $(41,7 \%)$ o problema surgiu, no geral, com intensidade menor do que no grupo do DDS, nos dez primeiros meses, dos quais 4 no primeiro mês. Dois casos apresentaram discreta erupção cutânea, temporária, com aspecto de vasculite.

A melhora clínica nos casos TR e $\mathrm{B}$, não incluidos ras Tabelas, foi também mais precoce.

A partir do oitavo mês a evolução clínica, com as exceções já referidas, processou-se mais lentamente, em ambos os grupos, com um certo paralelismo.

Embora estes achados estejam concordes, de modo geral, com os relatos da literatura especializada, em nossa experiência pessoal com tratamentos já de quatro anos seguidos, com a rifampicina, este evoluir admite exceções. A insuficiência de meios laboratoriais não nos permite falar em resistência, inadequação de dosagem ou outro fator. Apenas registramos o fato da possibilidade de aparecimento de novas lesões, e em um único caso, a reativação na borda de lesões involuídas. Estes acontecimentos não foram observados neste grupo experimental.

Em que pesem tais ressalvas, os achados nestes grupos experimentais permitem aceitar que, pelo menos até o oitavo mês, as melhoras clinicas são mais precoces e evidentes com o emprego da rifampicina.

$O$ estabelecimento dos índices bacterioscópico e morfológico constitui fato importante na avaliação das respostas à diferentes terapias. No entanto, há ainda con- 
BELDA, W. et al. Estudo comparativo das médias móveis, dos indices baciloscópico e morfo16gico, em pacientes de hanseniase virchoviana tratados pela rifampicina e pela diaminodifenil-sulfona. Rev. Saúde públ., S. Paulo, 13:80-91, 1979.

dições restritivas. As lesões, com ou sem o mesmo tempo de evolução e aspecto clínico, nos diferentes sitios do tegumento cutâneo, não apresentam a mesma concentração bacilar. Por outro lado, é característica da forma virchoviana a lentidão com que os bacilos ou restos bacilares são removidos dos tecidos parasitados.

$O$ indice morfológico parece ser mais indicado na avaliação do efeito terapêutico, já que se aceita que os bacilos não típicos, seja em termo de coloração irregular, de tamanho ou granulação, são inviáveis. Resta a dúvida da possibilidade da regeneração e nova reprodução de tais bacilos. Por outro lado, não há ainda interpretação segura para o papel do chamado bacilo persistente. Já nos referimos ao fato de, em nossa experiência, serem pouco freqüentes os casos de baciloscopia inicial com altos percentuais de bacilos integros.

Em que pese esta relatividade, na rotina diária estes indicadores têm sua importância.

A escolha de oito locais diferentes para a colheita de material teve em mira diminuir os erros da avaliaçăo de tais indices, embara obviamente pudesse também ser causa de erro, pelo fato apontado da diferença de concentraçāo bacilar.

$\mathrm{Na}$ avaliação a que nos propusemos, para minimizar o efeito da variação causal, empregamos a técnica das médias móveis para estudar a evolução das médias dos índices baciloscópico e morfológico.

As curvas correspondentes são apresentadas nas Figs. 1 e 2 . No simples observar da Fig. 1, relativo à evolução dos indices morfológicos, evidencia-se diferença de comportamento. Esta diferença é estatisticamente significante, ao nivel de $5 \%$, no teste de Kolmorogow-Smirnov $\left(\mathrm{K}_{\mathrm{D}}=7^{*}\right)$. Concordando com o achado clínico, a rifampicina evidenciou ação mais rápida sobre o bacilo de Hansen, do que o DDS.

Tendo em conta a morosidade com que o organismo se desfaz dos bacilos, não nos surpreendeu a impressão de curvas equiva- lentes na evolução dos índices morfológicos (Fig. 2). O teste de Wald-Wolforwitz mostra-se não significante ao mesmo nivel crítico de 5\%. Este achado destoa de alguns resultados obtidos por outros autores.

Fato que confirma as observações da rotina clínico-baciloscópica é a grande variação individual dos indices encontrados. No entanto, à medida que o tratamento se prolonga e se mostra eficaz, independentemente dos esquemas empregados, tanto em termos de índice baciloscópico como morfológico, esta variação tende a diminuir (Figs. $3,4,5$ e 6 ).

\section{CONCLUSOES}

Com as ressalvas apresentadas, nas condições da experimentação realizada, podemos aceitar:

a) pelo menos nos meses iniciais (até 0 oitavo), as melhoras clínicas da hanseniase virchoviana foram mais nítidas sob a ação da rifampicina que da diaminodifenil-sulfona:

b) a redução do indice morfológico, em termos de diminuição de bacilos viáveis, foi mais precoce e mais intensa no tratamento com a rifampicina, em comparação ao processado no tratamento com a diamino-difenil-sulfona;

c) não há diferença significativa na redução dos índices baciloscópicos em ambos os esquemas de tratamento empregados;

d) embora menos intensa, a reaçāo de eritema nodoso foi mais precoce e mais incidente no tratamento pela rifampicina.

Estas conclusões nos levam a acreditar que seria recomendável, pelo menos como tratamento incial, o emprego da rifampicina na hanseniase virchoviana. 
BELDA, W. et al. Estudo comparativo das médias móveis, dos indices baciloscópico e morfológico, em pacientes de hanseniase virchoviana tratados pela rifampicina e pela diaminodifenil-sulfona. Rev. Saúde pübl., S. Paulo, 13:80-91, 1979.

RSPUB9/452

BELDA, W. et al. IA comparative study of the variable averages of the bacilloscopic and morphologic indexes in virchowian hansen patients treated with rifampicin and with diamine-diphenyl-sulfone.] Rev. Saúde públ., S. Paulo, $13: 80-91,1979$.

ABSTRACT: The clinical and bacilloscopic results obtained in a comparative study of the therapeutic action of rifampicin and DDS in the treatment of the virchow form of Hansen's disease are presented. Two relatively homogeneous groups of 24 and 23 patients were observed during periods ranging from 12 to 24 months. The results demonstrated the superiority of the action of rifampicin during the first months of treatment, both in clinical aspects and in relation to the reduction of viable bacilli. Rifampicin is recommended for treatment of the virchow form of Hansen's disease, at least at the begining of the treatment.

UNITERMS: Rifampin. Leprosy, drug therapy.

\section{REFERENCIAS BIBLIOGRAFICAS}

1. BACCAREDDA-BOY, A. \& BERTAMINO R. Osservazioni cliniche sulla rifampicina nella lepra lepromatosa. In: Simposio Nazionale sulla Rifampicina. Roma, 1970. Roma, 1970. v. 3, p. 197-200.

2. BELDA, W. et al. Observações sobre o emprego da rifampicina em hansenianos aparentemente sulfono-resistentes. Hansenol. int. 1:79-91, 1976.

3. HORGENSEIL, L. M. \& REES, R. J. W. Effect of a single dose of rifampicin on the infectivity of nasal discharge. Leprosy Rev., 46(Supl.):147, 1975.

4. LEIKER, D. L. \& KAMP, H. First results of treatment of leprosy with rifadin. Leprosy Rev., 41:25-30, 1970.

5. MENEGHINI. C. L. et al. La rifampicina nell trattamento della lepromatose (Osservazioni su 57 casi). In: Simposio Nazionale sulla Rifampicina. Roma, 1970. Roma, 1970. v. 3, p. 169-73.

6. OPROMOLLA, D, V. Primeiros resultados com a "Rifamicina SV" na lepra lepromatosa. In: Congresso Internacional de Leprologia, 8\%, Rio de Janeiro, 1963. Anais. Rio de Janeiro, Serviço Nacional de Lepra, 1963. v. 2, p. 346-55.

7. PISACANE, C. et al. La nostra esperienza nel trattamento della lepra con Rifampicina. In: Simposio Nazionale sulla
Rifampicina. Roma, 1970, Roma, 1970. v. 3, p. 201-3.

3. REES, R. J. M. Experimental and clinical studies on rifampicin in treatment of leprosy. Brit. med. J., 1:89-92, 1970.

9. REES, R. J, W. Rifampicin: the investigetion of a bacteriocidal anti leprosy drug. Leprosy Rev. 46(Suppl.):121. 1975.

10. SHEPARD, C. C. et aI. Rapid bacteriocical effect of rifampin on Myco. leprae. Amer. J. trop. Med. Hyg., 21:446-9. 1972.

11. SHEPARD, C. C. et al. Rifampin and Myco. leprae, Int. J. Leprosy, 40:459-60, 1972.

12. SOUZA-LIMA, L. \& ARANTES, F. Resistência do bacilo de Hansen à quimioterapia. In: Congresso Internacional de Leprologia, 89, Rio de Janeiro, 1963. Anais. Rio de Janeiro, Serviço Nacional de Lepra. 1963. v. 2, p. 414-37.

13. TRIMIGLIOZZI, G. et al. Osservazioni preliminari sulla terapia della lebbra con rifampicina. G. ital. Derm. Minerva derm., $45: 215-6,1970$.

Recebido nara publicação em 26/10/197\% Aprovado sara nublicação em 22/03/197\% 